\title{
The measurement of targeting intentions in complex welfare states: a proposal and empirical applications
}

Sarah Marchal

Wim Van Lancker

This is a pre-print of an article published in Social Indicators Research. The final authenticated version is available online at https://doi.org/10.1007/s11205-018-1995-Z.

\section{Introduction}

The debate on targeting social welfare is as old as the debate on the welfare state, both in the academic and in the political arena. Indeed, the allocation of resources is at the very core of the welfare state (Mitchell et al. 1994). Although the concept of targeting has been defined rather loosely in the welfare state literature, the overlapping consensus is that it concerns the question: who should get what and how should they get it? Benefit schemes differ according to their objectives and their underlying logic, yet it is hard to imagine a benefit that is not targeted at a particular category of beneficiaries.

A longstanding question, however, is whether benefit schemes should be targeted by level of income within those categories. Here, welfare states tend to differ greatly as the choices with regard to welfare provision made today are path dependent and reflect each country's historical trajectory; the contrast between the 'universal' social-democratic welfare states of the Scandinavian countries and the 'targeted' liberal welfare states in the Anglo-Saxon world being among its most wellknown examples.

One important piece of the puzzle that is largely missing in the literature on targeting is the question of policy design, i.e. whether benefit schemes are actually intended to end up with certain income groups or not. Benefits may appear targeted (or not) because of so-called composition effects: universal child benefits will appear to be targeted if poor families have more children on average, while educational benefits that are intentionally targeted towards low income families may appear to be regressive given the particular composition of the student population. Most studies make abstraction of this fact, and operationalize targeting as the outcome of the redistributive process rather than as the intention built into the benefit program. Whereas this is a valid approach for some 
research questions, this is not helpful to address the question how policies should be designed in order to yield certain redistributive outcomes since composition and design effects are conflated. In this article we propose, discuss, and test a new approach to measuring targeting intentions in complex welfare states. In doing so, it is our aim to develop and apply a complementary institutional targeting indicator that captures the design of benefits. Such indicator contributes to the literature in three ways: 1) it summarizes policy design into one parameter; 2) it enables to trace important policy changes and trends over time; and 3) it highlights and helps understand the role of policy design in the redistributive process.

The above-mentioned difference between categorical and income targeting on the one hand and between universal versus targeted welfare states on the other, are testament to the conceptual opacity that obfuscates the scientific discussion about targeting. For that reason, we will, first of

all, pay due attention to the concept of targeting intentions: what do we precisely mean by it, and how should it be measured appropriately? Second, we will discuss to what extent a measure of targeting design should be able to meaningfully capture the complexities of different benefit systems. Third, on the basis of a hypothetical income distribution, we will test different approaches towards measuring targeting, and discuss to what extent they fulfil the conditions necessary for being a useful indicator. Finally, we will demonstrate the potential of the proposed targeting indicator on the basis of publicly available datasets.

\section{Revisiting an old question: who gets what?}

The aim of this study is to construct an indicator to properly measure the targeting intentions built into the benefit systems of modern welfare states. Before doing that, it needs to be strictly defined what we mean by 'targeting intentions'. Four issues are relevant to discuss here.

First of all, in the literature the concept of targeting is usually treated in a rather vague way. It is not always clear how it is distinct from related concepts such as universalism, selectivity or meanstesting. In their seminal 1998 article The Paradox of Redistribution, for instance, Korpi and Palme consider universalism and targeting as two extremes on one continuum: "whether social policies should be targeted or universal, that is, should they be organized for the poor only or should the welfare state include all citizens" (1998: p. 661, our emphasis). In their view, benefit systems are 
either universal or targeted. Recent studies on the issue, however, define targeting as a feature of benefit systems distinct of universalism (see also van Oorschot and Roosma 2016). Brady and Bostic (2015), Marx et al. (2016) and Van Lancker and Van Mechelen (2015), for instance, argue that benefits can be universal and targeted at the same time, echoing Theda Skocpols 'targeting within universalism' (1991). In that view, the opposite end of universalism is selectivity ('who is entitled?') while targeting is about the allocation of resources across those who are entitled ('what do they get?'). Here a distinction is made between entitlement on the hand and benefit amounts on the other. On the one hand, universal benefits cover all citizens while selective system do not cover all of them. It is important to realize that all benefits are selective in one way or the other, since they are usually meant to cover a particular group of citizens such as pensioners, the unemployed, or children. However, if every one of the 'reference group' is covered by the benefit, it is considered universal (Van Lancker et al. 2015). A useful example is that of a universal child benefit system covering all families with children versus a selective child benefit system covering only a selection of the reference group based on certain characteristics, such as working families with children, working families with young children, or low-income families with children. On the other hand, targeting is a continuum ranging from low-income targeting (lower incomes get more) over no targeting (everyone is entitled to equal amounts) to high-income targeting (higher incomes get more). Targeting hence may occur in benefit systems that are either universal or selective in nature. The only issue, however, is that selective systems are always targeted if entitlement is restricted to a specific group of people based on income. We will come back to this issue below. Means testing, then, is a means to an end, a way to determine who gets what, not a distinct feature of benefit systems.

Second, targeting is usually regarded an outcome of redistributive process rather than a feature of benefit design. When Korpi and Palme (1998) regarded targeting as being anathema to effective reduction of inequality, they actually meant the systems that appear targeted, i.e. the share of transfers that accrue to the lowest incomes. The obvious problem here is that policy intentions do not necessarily match policy outcomes. If all children are entitled to an equal benefit amount, but only low income families have children, then child benefits will appear targeted towards the lowest incomes. The policy design, however, is not targeted. The proper measurement of targeting intentions therefore needs to be isolated from these so-called composition effects. 
Third, Barr (2001) identifies two redistributive principles within contemporary welfare states: horizontal redistribution (between groups over the lifespan) and vertical redistribution (from rich to poor). While benefit programs in many cases embody both principles at the same time, it is generally possible to identify a 'dominant logic'. The traditional social insurance programs, for instance, predominantly focus on horizontal redistribution. They aim to smooth consumption over different life phases by insuring against the loss of living standards upon the occurrence of certain social risks that impact on one's market earning potential (Cantillon and Van Mechelen 2014; Bonoli 2007; Barr 2001). Clear examples are contributory-based unemployment, disability, pensions or sickness benefits. In addition to these (often earnings-related) contributory benefits, certain non-contributory benefits may also be founded on such horizontal logic. For instance, child benefits redistribute the costs of raising children over the entire population as they redistribute from childless persons to persons with children. Here, the idea is not to insure against the (potential) loss of market income upon the birth of a child but rather to reimburse (some of) the costs associated with childrearing. In contrast, programs undergirded by a vertical redistribution logic are designed to redistribute resources from richer to poorer groups. Clearly, means-tested minimum income benefits aim to provide a social floor to the very poor, and they are generally financed through general tax revenues. Also other benefits explicitly entail a vertical redistribution focus, for instance various means-tested cost-compensating measures, such as housing allowances. Yet also many of the larger social insurance programs incorporate characteristics that ensure that there is some vertical redistribution, for instance through limiting the earnings-related logic with a maximum benefit. The same is true for child benefits, which often combine benefits for all children with additional allowances for poor families. In addition, in many cases different benefit programs will be relevant at the same time, each one of those with their own main redistribution logic. A measure of targeting intentions hence needs to be able to cope with both contributory and noncontributory types of benefits.

A final, related issue refers to how one identifies the reference group of different benefit programs. In most welfare states, the target population is predominantly based on categories of people, be it families with children, the elderly, the disabled, etc. This approach is called categorical targeting (i.e. by category), or, in the words of Akerlof (1978) 'tagging'. Alternatively, beneficiaries may be identified based on their income or assets. Public resources are allocated to certain groups in case their income falls short of a certain predefined threshold. In that case a means test is usually applied. 
Means testing on the basis of income is riddled with difficulties and pitfalls, for instance the issue of how to acquire up-to-date income information and which kind of incomes should be included (Whiteford et al. 2003). For that reason, while policymakers intend to allocate public resources to low income families, they might opt to use categories as proxies for low income families. An example voiced by both Akerlof (1978) and Smolensky et al. (1995) are female-headed households. This is where the blurred lines between selectivity and targeting become relevant. A selective benefit, for instance founded on a particular category of beneficiaries such as single mothers, can be more or less targeted towards lower income groups. Think of additional child benefits for single parents irrespective of their social background, which exists e.g. in Norway, or additional child benefits for single parents living on low incomes, which exists e.g. in Belgium. However, if categories are used as proxies to identify low incomes, selective systems are targeted towards low incomes as well. This implies that while selective systems will be targeted towards lower incomes in many cases, some selective benefits will be more targeted towards lower incomes than others. An indicator measuring targeting intentions should be able to capture these differences in benefit design and to isolate the issue of targeting from the coverage of reference groups.

Given all this, in this paper we will apply the following definition of targeting in order to gauge the vertical redistribution logic of social benefits: the extent to which benefits are intended to be higher or lower for people with higher or lower incomes, including both non-contributory and contributory benefits as well as universal and selective systems.

\section{Targeting in complex welfare states}

Modern welfare states are complex machineries that almost never adhere to a purely horizontal or vertical redistribution logic. In reality, the hybrid nature of benefit systems combines contributory and non-contributory benefits, uses different sources of financing, embodies different objectives, and has elements of horizontal as well as vertical solidarity mechanisms. Since targeting intentions gauge the extent to which benefits are meant to allocate more resources to one income group visà-vis other income groups, and are conceptually distinct from universalism and selectivity, an indicator capturing this should also be able to handle the kind of complexities inherent to welfare states.

In table 1, we provide an example of conceivable yet hypothetical benefit designs. Think of the different rows as different households or individuals ranked according to their current income 
position, with the benefit unit on rank 0 being poorer than benefit unit 1, and so on. In hypothetical country A, each of these benefit units receive a benefit of an equal amount (in casu 50). This is the quintessential example of a universal benefit, where everyone (of the reference group) is entitled to a benefit and everyone receives the same amount. A common real-world example of such a benefit is a universal child benefit for families with children.

Table 1. Examples of benefit distributions across 11 individuals, ranked from low to high income

\begin{tabular}{lllllllll}
\hline Rank & $\begin{array}{l}\text { Universal } \\
\text { (A) }\end{array}$ & $\begin{array}{l}\text { Selective } \\
\text { (B) }\end{array}$ & $\begin{array}{l}\text { Targeting } \\
\text { within } \\
\text { universalism } \\
\text { (C) }\end{array}$ & $\begin{array}{l}\text { Targeting } \\
\text { within } \\
\text { selectivism } \\
\text { (D) }\end{array}$ & $\begin{array}{l}\text { Non-linear } \\
\text { targeting } \\
\text { within } \\
\text { universalism } \\
\text { (E) }\end{array}$ & $\begin{array}{l}\text { Non-linear } \\
\text { targeting } \\
\text { within } \\
\text { selectivism } \\
\text { (F) }\end{array}$ & $\begin{array}{l}\text { Non-linear } \\
\text { targeting } \\
\text { within } \\
\text { selectivism } \\
\text { - bis }\end{array}$ \\
\hline $\mathbf{0}$ & 50 & 50 & 65 & 65 & 10 & 10 & 0 & $\begin{array}{l}\text { Regressive } \\
\text { (H) }\end{array}$ \\
\hline $\mathbf{1}$ & 50 & 50 & 60 & 60 & 10 & 10 & 0 & 10 \\
\hline $\mathbf{2}$ & 50 & 50 & 58 & 58 & 50 & 50 & 50 & 30 \\
\hline $\mathbf{3}$ & 50 & 0 & 55 & 55 & 40 & 40 & 40 & 40 \\
\hline $\mathbf{4}$ & 50 & 0 & 53 & 53 & 30 & 30 & 30 & 40 \\
\hline $\mathbf{5}$ & 50 & 0 & 50 & 50 & 20 & 20 & 20 & 40 \\
\hline $\mathbf{6}$ & 50 & 0 & 45 & 45 & 10 & 10 & 10 & 40 \\
\hline $\mathbf{7}$ & 50 & 0 & 40 & 40 & 10 & 0 & 0 & 40 \\
\hline $\mathbf{8}$ & 50 & 0 & 20 & 0 & 10 & 0 & 0 & 40 \\
\hline $\mathbf{9}$ & 50 & 0 & 10 & 0 & 10 & 0 & 0 & 40 \\
\hline $\mathbf{1 0}$ & 50 & 0 & 5 & 0 & 10 & 0 & 0 & 40 \\
\hline
\end{tabular}

A targeted benefit on the other hand directs different benefit amounts according to the income situation of a person, household or benefit unit. In Table 1 we present a selection of potential variations in benefit allocation according to income. In country B, the benefit is only awarded to persons under a certain income ceiling. This is what we called supra a selective benefit scheme (and it overlaps with low income targeting). Country $\mathrm{C}$ has designed its benefit in such a way that - although everyone receives a benefit - persons with a lower income receive a higher benefit. This is commonly referred to as 'targeting within universalism'. The same is true for country D, although here the highest incomes are excluded from the system. Country $\mathrm{H}$ is its antipode, reflecting a regressive benefit system in which higher income groups receive higher benefit amounts. Ideally, we would like our indicator to be able to cope with these different targeting designs. The indicator also needs to take due account of less straightforward benefit systems. In the age of activation, 
many countries have implemented benefits that increase with earnings up to a certain point only to be tapered away subsequently (countries E and F). Finally, it is perfectly realistic for some benefits to only exist for higher income cases (country G). Often, this is because an additional condition applies that people should be in-work or have a certain level of earnings. Earnings-related tax credits or in-work benefits are a case in point.

To meaningfully summarize and compare intended targeting design across countries, we need an indicator that is able to capture the differences between complex benefit systems in a single metric. Self-evidently, such an indicator also needs to adhere to minimal quality standards. A large body of work on social indicators stemming from the so-called 'social indicator movement' has established the properties a useful indicator of policy should adhere to (e.g. Atkinson et al. 2002; Land 1983). Drawing on this literature, we adopt as a rule that an indicator of targeting intentions should be 1) comparable across and within countries over time; 2) responsive to policy changes; and 3) have a clear interpretation. The comparability requirement means that the indicator should have exactly the same meaning in different contexts and benefit systems. A value of 0 , for instance, should mean the same thing in different contexts and across different benefit systems. That means, importantly, that the value of the indicator cannot be dependent on benefit levels (see also Moene and Wallerstein 2001). A value of 0 in country $\mathrm{X}$ needs to reflect the same extent of targeting as a value of 0 in country $\mathrm{Y}$, even if country $\mathrm{X}$ is much more generous than country $\mathrm{Z}$. Since it is a policy indicator, it should also properly reflect policy changes. The interpretability requirement means that the indicator must have what Atkinson et al. (2002, p. 21) call 'intuitive validity'. For instance, there should be agreement that a movement of the indicator in a particular direction represents more or less targeting.

\section{Choosing an appropriate indicator}

In this section we will first review the literature on tax and social policy measurement and subsequently propose a measurement method that is in our view suitable to capture targeting intentions. From the onset it should be clarified that measurement and data are not completely separable. An indicator of targeting intentions must be built on data that captures the design of benefit systems, and is available in a form that resembles our hypothetical income distributions 
shown in Table 1. So we need to establish the kind of data we need first to subsequently be able to identify a measurement method that is able to summarize that data into one single metric that fulfills the requirements outlined above.

\subsection{Institutional data}

The assessment of intended policy design builds on institutional data, that capture the applicable institutions and legal regulations. An obvious example of institutional data are descriptions of legal rules, such as those captured in the European Commission's comparative MISSOC database (www.missoc.org), but the format of such data is not readily quantifiable. A common form of quantitative institutional data are model family simulations. These are calculations of the net disposable income of a hypothetical family according to relevant tax benefit rules. As the model family is completely determined by the researcher in line with his or her research question, the resulting income and income components fully capture tax-benefit design. It is an approach that is often applied to compare benefit generosity cross-nationally or over time, as changes cannot be brought back to composition effects, but by definition only reflect actual policy changes. In the literature, this approach is often used to capture the generosity of social protection measures (Bradshaw and Finch 2002; Nelson 2013; Gough et al. 1996; Immervoll 2012). Several institutions already collected model family simulations in institutional datasets that are available to the broader public. Relevant examples include the CSB MIPI data set (Van Mechelen et al. 2011); the SaMIP dataset (Nelson 2007); and the OECD Benefits and Wages output (OECD 2014).

Yet, targeting design is not limited to the net income or generosity of income components in one situation, but refers to how income components are distributed over different income situations. A targeting intentions indicator should hence summarize policy design over a broader income range. Tax design scholars are confronted with a similar problem when aiming to represent the inherent progressivity of tax systems. Early proposals were made by Musgrave and Thin (1948), who discussed the (then) newly revised tax design in the US. They calculated the tax liability of a married couple with 1 child at different points in the income distribution to serve as input to their structural progressivity indicators, constructed to evaluate and compare intended tax rates. The aim of these indicators was to distinguish between proportional, regressive and progressive tax system designs. Some of the measures they proposed are still being used by the OECD in its annual Taxing Wages report, albeit for a broader range of family types (Paturot et al. 2013; Joumard et al. 2012; 
OECD 2015). Even though these stylized measures have been criticized in the past (e.g. by Kakwani, in 1986), the OECD argues that structural progressivity indicators are needed as they allow to assess the progressivity of certain taxes in isolation, and precisely because they provide estimates of progression rates along the income scale. Finally, they can help to standardize crosscountry comparisons (Paturot et al. 2013).

\subsection{Measuring policy design}

Examples of indicators that aim to summarize the overall design of benefits rather than taxes are relatively scarce. Two recent examples are provided by Joumard et al. (2012). They present a progressivity index for pensions, that builds on future pension payments simulated on current personal gross earnings (see also OECD 2011, p. 138). The progressivity index of pensions is then calculated as 100 - 100 times the ratio of the Gini index of these simulated future pension payments to the Gini index of current personal gross earnings. The calculations are based on the current pension rules. A value of 100 indicates that the pension system is a flat basic pension, which is considered to be the most progressive pension system. They also developed an indicator that measured the progressivity of unemployment benefits. For this, they compare the net replacement rates of low (earning $67 \%$ of the average wage) and high (earning $150 \%$ of the average wage) income earners. The larger the difference, the more progressive they deem the unemployment benefit system.

In a recent paper, Nelson et al. (2016) also focused on the progressivity of unemployment insurance replacement rates. They calculated the theoretical replacement rates for a hypothetical single person with former incomes ranging from 50 to $100 \%$ of the average wage. Consequently, they calculated the concentration coefficient of these replacement rates over former incomes (i.e. 50 $100 \%$ of the average wage, by 1 percentage point increments) in order to assess the extent to which replacement rates are equally guaranteed. The concentration coefficient is a commonly used metric to measure targeting outcomes, i.e. the extent to which benefits end up among lower ranked income groups (for a famous application: see Korpi and Palme (1998)). In contrast to these progressivity measures, that focus on tax or replacement rates, we would like to distinguish between universal or targeted benefit amounts, which aligns with our definition of targeting intentions, i.e. the extent to which benefits are intended to be higher or lower for people with higher or lower incomes. 
Studies that aim to operationalize targeting in line with this interpretation are scarce. Jacques and Noël (2015) recently proposed to take the share of means-tested benefits in total benefit receipt as an imperfect proxy of the targeting design of benefit schemes, but such an operationalization does not solely capture intended targeting design, but also socio-economic and demographic context. A different proposal was made by Van Lancker and Van Mechelen (2015). They aimed to measure the targeting design of child support packages. The indicator (henceforth TIVLVM) captures the average percentage increase in child support for a model family with a lower income vis-à-vis the same model family with a higher income.

Specifically, the indicator was calculated as

$$
T I V L V M=1-\frac{1}{n} \sum_{i=1}^{n} \frac{x_{i}}{x_{i+1}}
$$

with $x_{i}$ the child benefit package in the lower income case, and $x_{i+1}$ the child benefit package in the higher case. TIVLVM hence shows the percentage a child benefit package to a lower ranked family is on average higher (or lower) than for a higher ranked family. The indicator was subtracted from 1 in order to obtain negative values for targeted benefits and positive values for benefits targeted to higher incomes. A value of zero refers to a benefit where every family receives the same amount (a universal benefit).

Van Lancker and Van Mechelen (2015) based their indicator on model family simulations of net disposable income and its components for a specific household type at different points in the income distribution (no income, at minimum wage (if such existed), at average wage, at doubleearner average wage). The clear advantage of this indicator is that data requirements are relatively limited, although there are obvious risks to basing an assessment on a limited number of cases. More importantly, its interpretation is very straightforward. Unfortunately, the indicator cannot cope with selective benefits, as targeting is always expressed as a percentage of benefit amounts higher up in the income distribution. This necessarily assumes that higher incomes will still receive benefits, an assumption that is far from plausible for a number of benefit schemes.

\subsection{A versatile institutional targeting intentions indicator}

From the above, it is clear that - at least to our knowledge - there currently is no targeting intentions indicator that copes with the complexities of the hypothetical world outlined in Table 1. In this 
paper we propose to apply the concentration coefficient (Kakwani, 1977) on institutional data, and assess whether such measurement method has the potential to serve as an indicator of targeting intentions. Nelson et al. (2016) already proposed to use the concentration coefficient on replacement rates of hypothetical single person households. Rather than assessing progressivity, we want to assess whether a concentration coefficient applied on institutional model family simulation data will meaningfully gauge the extent of targeting in different benefit systems, and capture the difference in the strength of targeting across countries.

In essence, a concentration coefficient offers a measure of the extent to which benefits end up with richer or poorer entitlement units. Institutional data, that capture how a tax benefit system is designed to work, regardless of contextual factors, allow to assess the extent to which benefits are intended to end up with richer or poorer entitlement units. Formally, the concentration coefficient is expressed as follows:

$$
T I_{C C}(B, Y)=-2 \operatorname{Cov}\left(\frac{B}{\mu(B)},(1-G(Y))\right.
$$

with benefit $\mathrm{B}$, income distribution $\mathrm{Y}$ and $\mathrm{G}(\mathrm{Y})$ the cumulative distribution function of $\mathrm{Y}$. Graphically, the concentration coefficient measures the surface between the cumulative distribution function of benefits over the income distribution, and the $45^{\circ}$ line, where every entitlement unit receives the same benefit amount. As long as it is calculated on positive values, the concentration coefficient assumes values between -1 and 1 . A value of -1 implies that the poorest entitlement unit in the income distribution receives all the benefits, whereas a value of 1 indicates that all benefits are targeted at the richest entitlement unit. A value of zero indicates that the cumulative distributive function of a benefit coincides with the $45^{\circ}$ line, or that there is no association between the benefit amounts and the entitlement unit's place in the income distribution. In other words, every entitlement unit receives the same benefit amount; it is not targeted.

In Table 2, we calculate the concentration coefficient for each of the targeting designs discussed in Table 1, and assess whether it is indeed in line with our requirements of summarizing targeting intentions. We also compare the concentration coefficient with the targeting indicator proposed by Van Lancker and Van Mechelen, discussed above. Clearly, the concentration coefficient has a number of important advantages. The universal benefit is identified as such, with a concentration coefficient equal to zero. The selective system has the lowest value, at -0.8 , whereas the regressive 
system shows a positive value for the concentration coefficient, indicating that higher ranked benefit units receive higher benefit amounts. Also for the other, more complex systems, the values of the concentration coefficient align with our intuitive assessment of more or less targeted systems. Importantly, as it is a measure of association, it is able to handle non-linear targeting. In contrast to the TIVLVM indicator, it can handle targeting within selective systems.

Table 2. Examples of benefit distributions across 11 individuals, ranked from low to high income

\begin{tabular}{|c|c|c|c|c|c|c|c|c|}
\hline Rank & Universal & Selective & $\begin{array}{c}\text { Targeting } \\
\text { within } \\
\text { universalism }\end{array}$ & $\begin{array}{c}\text { Targeting } \\
\text { within } \\
\text { selectivism }\end{array}$ & $\begin{array}{l}\text { Non-linear } \\
\text { targeting } \\
\text { within } \\
\text { universalism }\end{array}$ & $\begin{array}{l}\text { Non-linear } \\
\text { targeting } \\
\text { within } \\
\text { selectivism }\end{array}$ & $\begin{array}{l}\text { Non-linear } \\
\text { targeting } \\
\text { within } \\
\text { selectivism } \\
\text { - bis }\end{array}$ & Regressive \\
\hline 0 & 50 & 50 & 65 & 65 & 10 & 10 & 0 & 10 \\
\hline 1 & 50 & 50 & 60 & 60 & 10 & 10 & 0 & 20 \\
\hline 2 & 50 & 50 & 58 & 58 & 50 & 50 & 50 & 30 \\
\hline 3 & 50 & 0 & 55 & 55 & 40 & 40 & 40 & 40 \\
\hline 4 & 50 & 0 & 53 & 53 & 30 & 30 & 30 & 40 \\
\hline 5 & 50 & 0 & 50 & 50 & 20 & 20 & 20 & 40 \\
\hline 6 & 50 & 0 & 45 & 45 & 10 & 10 & 10 & 40 \\
\hline 7 & 50 & 0 & 40 & 40 & 10 & 0 & 0 & 40 \\
\hline 8 & 50 & 0 & 20 & 0 & 10 & 0 & 0 & 40 \\
\hline 9 & 50 & 0 & 10 & 0 & 10 & 0 & 0 & 40 \\
\hline 10 & 50 & 0 & 5 & 0 & 10 & 0 & 0 & 40 \\
\hline VLVM & 0 & & -0.35 & & -0.13 & & & 0.11 \\
\hline $\mathrm{CC}$ & 0 & -0.8 & -0.28 & -0.37 & -0.19 & -0.40 & -0.33 & 0.14 \\
\hline
\end{tabular}

In sum, we argued that a targeting intentions indicator should be comparable across countries, responsive to policy changes and intuitively interpretable. We demonstrated that the concentration coefficient calculated on institutional data captures policies in a satisfying and understandable way. Even though it is less intuitive than some of the other measures discussed above, values can be compared across countries with the same distribution, and rankings are in such a case meaningful. In addition, the concentration coefficient is widely used as a measure of targeting outcomes. In this sense, its application on institutional data in order to capture targeting intentions is a logical step. 


\section{Applications using real-world data}

\subsection{Data}

In order to summarize targeting design, we first need data that reliably capture the design of benefit systems in the form discussed above. Here we use the OECD Benefits and Wages output data to assess differences in targeting design across countries, between benefit schemes and over time (http://www.oecd.org/els/soc/benefits-and-wages-country-specific-information.htm). The OECD Benefits and Wages model family simulation model allows to calculate net disposable income and income components for model families who are entitled to contributory unemployment insurance benefits (for different levels of prior earnings), to non-contributory benefits, or a combination of both. A major advantage of the OECD data over other institutional datasets is that it covers all OECD countries and EU Member States over a long period of time. Most countries are covered since 2001, with the exception of more recent OECD member countries.

The output data, which are freely available, contain the amounts of net disposable income and its different components, for various family types and with the model family making the transition from a gross income equal to $0 \%$ of gross average wage to $220 \%$, by a 1 percentage point increase at each step. This amounts to a highly stylized (and unequal) gross (before taxes and benefits) income distribution with a Gini coefficient equal to 0.93 that is the same for all countries and years ${ }^{1}$. This income distribution is limited to $220 \%$ of gross average wage. It hence excludes higher incomes that may - at a household level, in times of double-earnership - be quite common. Model family simulations by definition do not give a representative view of a country's population. Since it is our express aim to eliminate composition effects (and hence to capture targeting intentions rather than targeting outcomes), we do not consider this problematic. Yet a common critique on the use of model family simulations is that their limited representativeness may well make them superfluous, and conclusions based on them can be faulty, as they are driven by a selected family case that may be not at all relevant in a country. In Table A1 in the appendix we therefore show to what extent this stylized income distribution aligns with each nation's actual distribution. In all but

\footnotetext{
${ }^{1}$ All Gini coefficients and concentration coefficients reported in this paper are calculated with Van Kerm's (2009) sgini command for stata.
} 
one country more than two thirds of persons fall within the range of the fictional distribution of the OECD dataset. ${ }^{2}$

In what follows, we show the results of three empirical applications. The purpose is to assess whether the concentration coefficient applied to institutional data meaningfully gauges targeting intentions in complex welfare states, to what extent it is useful to understand differences in targeting intentions over time and between countries, and whether it is able to properly summarize policy design into one parameter.

\subsection{Application 1: Targeting design of non-contributory benefits in OECD countries, 2013}

We begin with a straightforward approach to measuring targeting intentions by focusing on noncontributory benefits for working-aged families. Since these benefits are not related to previous earnings, the amounts given to different income groups are a clear expression of targeting intentions $^{3}$. As one of the most common benefits, we first turn our attention to child benefits. Next, we include social assistance benefits, housing allowances and in-work benefits ${ }^{4}$. In doing so, we aim to assess to what extent welfare states target different benefits, and whether there are obvious differences between schemes.

\footnotetext{
${ }^{2}$ A further caveat is that we limit ourselves to very few model families. Alternatively, one could aim to align simulated data more to the real socio-economic and demographic situation in each country, or, if one wants to eliminate composition effects, to use a real population as input for detailed policy simulations with a micro simulation model, such as EUROMOD. Keeping this population constant between countries and over time should also allow to disentangle targeting intentions. In se, the problem remains the same: the selected population still brings its own composition effects, and will be more realistic for one country than for another. Focusing on the highly stylized OECD distribution that we use in this paper has the advantage of transparency and simplicity, with freely available data, at the cost of more realistic and representative data.

${ }^{3}$ In contrast, the benefit amounts in contributory schemes are usually tied to previous earnings, which makes it more complex to interpret targeting intentions. In section 5.4, we discuss the interpretation of targeting intentions for contributory benefit schemes.

${ }^{4}$ We follow the OECD classification of these different benefits. This is particularly relevant for the assessment of refundable tax credits. These are included as benefits if the OECD classifies these as in-work benefits or child benefits. If the OECD includes them as income taxes, they are not included in our indicator. In Figure A1 in the appendix we explore the impact of this classification on our targeting design measure.
} 
Figure 1 presents the concentration coefficients of child benefits received by a married couple (both partners aged 40) with 2 children aged 4 and 6 . Targeting intentions vary strongly across countries, ranging from -0.86 in the United States ${ }^{5}$, to 0 in Austria, Belgium, Denmark, Finland, Ireland, Israel, Japan, Luxembourg, Latvia, Sweden, Norway and Slovakia, and an exceptional 0.33 in Greece. Hence our indicator identifies ten of the countries in our sample as countries with a universal child benefit scheme. Furthermore, the measure indicates that in the large majority of countries child benefits are targeted to some extent, with exceptionally large values in the United States, Spain, Chile, Poland, the Czech Republic, Lithuania, the $\mathrm{UK}^{6}$ and New Zealand. These assessments align with our knowledge of the child benefit schemes in these individual countries. That the Scandinavian countries appear to have a universal child benefit comes as no surprise. Similarly, in Belgium, the child benefit system in 2013 was universal in design with only limited social supplements for certain categories of beneficiaries, such as the long-term unemployed or lone parent families. Highly targeted benefits in particular Eastern European countries, the US and the UK are equally unsurprising. The Greek child benefit scheme registers as regressive as in the underlying data, the family benefit increases with income, both nominally as relative to the earned income. Greek child benefits are indeed supplemented by employers in line with the gross salary. A similar case presents itself for Switzerland, where only employed persons are entitled to child benefits, funded by employers (for the unemployed, cash support for families with young children is covered through different benefits).

\footnotetext{
${ }^{5}$ Despite its functional equivalence to social assistance, the OECD classifies Temporary Assistance to Needy Families (TANF) as a child benefit since access is heavily conditioned on the presence of children in the household.

${ }^{6}$ The OECD classification includes the child tax credit under family benefits.
} 
Figure 1. Targeting design of child benefits for a couple with 2 children, over income range $0-220 \%$ of gross average wage, 2013, OECD countries

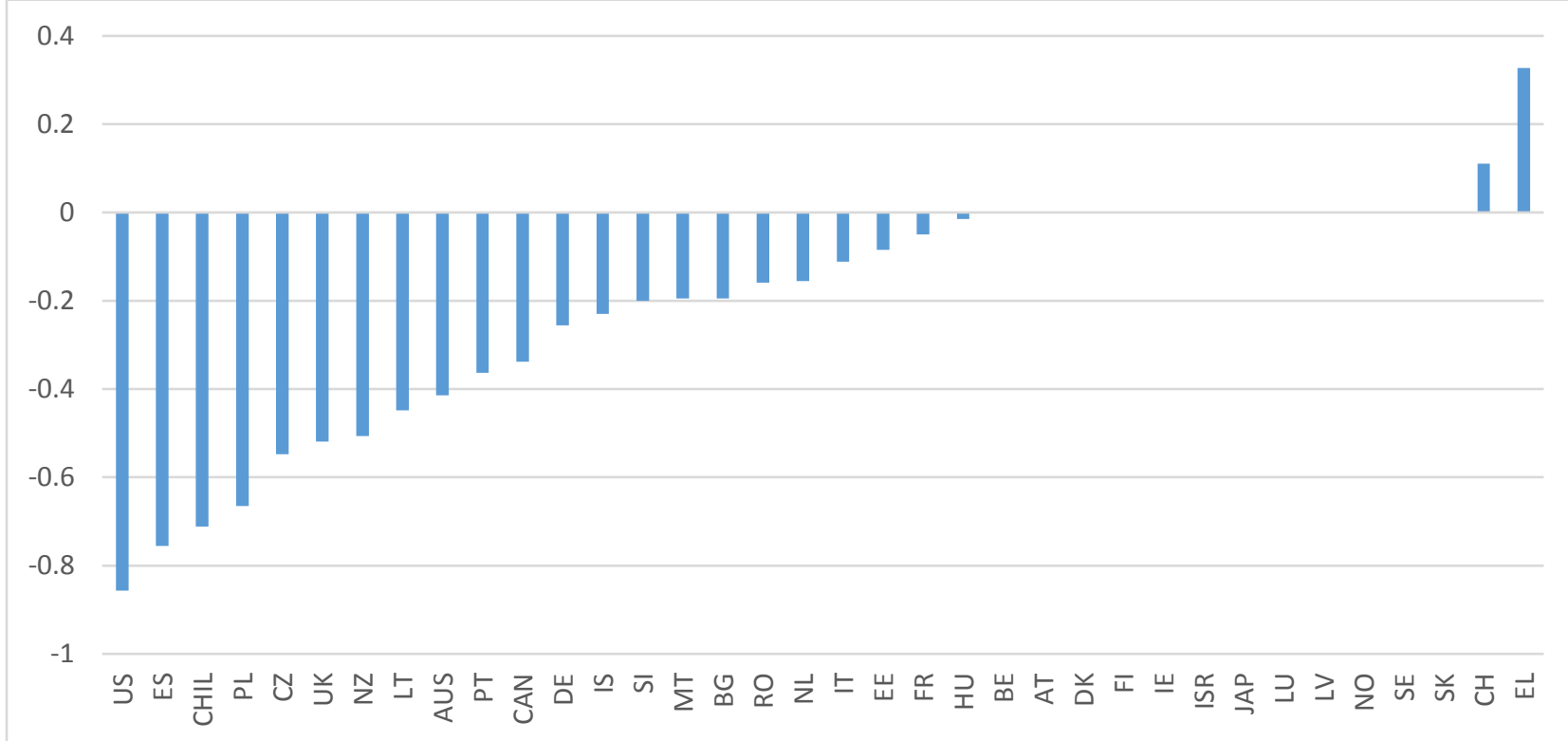

Note: no child benefits in Korea (KOR) and Turkey (TUR). Exact targeting indicator values are reported in Table A2 in the appendix.

Source: own calculations on the OECD Benefits and Wages output data (2014)

Broadly speaking, the targeting intentions measure calculated on the allocation of child benefits over a fictional distribution of a model family does seem to represent the policy design of child benefits in a satisfactory way. The distinction between universal, targeted and regressive benefits is clear. Yet what is the exact targeting design behind these summary values? In Figure 2, we zoom in on the cases of Germany, Finland and Portugal, with respective targeting design indicators of $-0.26,0$ and -0.36 . Our targeting indicator hence identifies Finnish child benefits as being universal, Germany as having a child benefit system that is slightly targeted towards lower incomes, and Portugal as having a child benefit system that is more strongly targeted towards lower income incomes. In figure 2, we show the child benefit relative to the annual gross average wage at each income level. It is immediately clear that benefit generosity differs substantially between the three countries. However, in this paper we are not interested in measuring the generosity of child benefits, but in the way the resources are allocated over income groups. 
In line with the values shown by the institutional targeting indicator, differences in targeting are quite pronounced. In Finland, regardless of the position in the stylized income distribution, the intended benefit amount is the same. Finland has a universal child benefit system akin to the hypothetical system A in table 1. In Portugal, however, child benefits are selective, and within the eligible income range still vary with incomes. The stacked distribution clearly indicates the used income thresholds in the definition of the benefit level according to the legal rules. Finally, Germany is somewhat of a special case. Child benefits are selective and targeted towards lower incomes, bar for a limited income range around half of the gross average wage. This shows the Kinderzuschlag, a benefit that was introduced in 2005 in order to support parents who would be able to secure their own livelihood without the need for social assistance, where it not for the presence of children in the household. The targeting indicator does cope with this non-linearity, and identifies the German child benefit system as a targeted scheme with a concentration coefficient of the benefits depicted in figure 1 of -0.26 . Of course, a value of -0.26 might also refer to a linearly, but less steeply targeted benefit. Some background knowledge of the system therefore remains - self-evidently - necessary.

Figure 2. Distribution of child benefits over stylized income distribution: couple with two children, gross income ranging from $0-220 \%$ of gross average wage, in $1 \mathrm{ppt}$ intervals

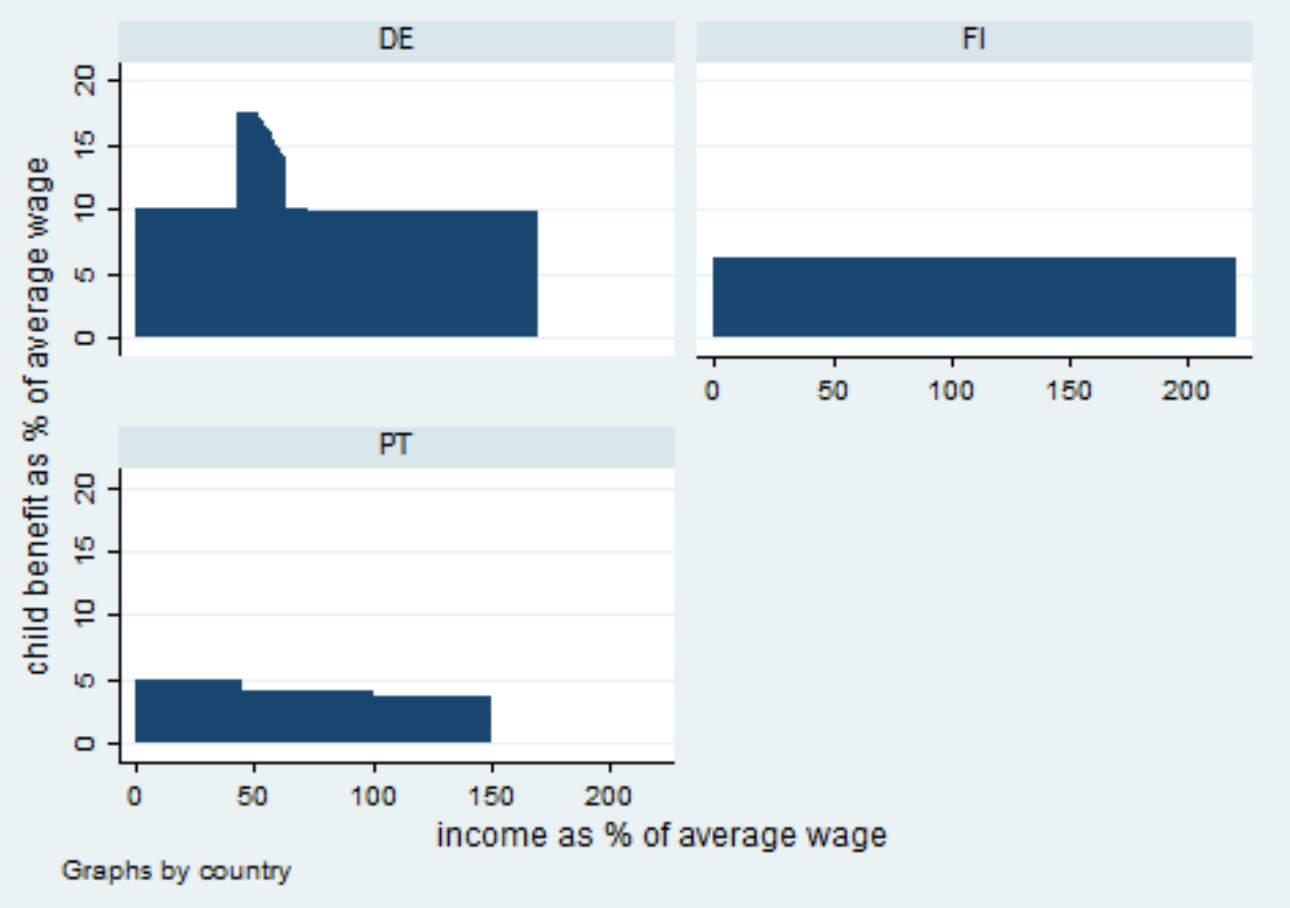

Source: own calculations on the OECD Benefits and Wages output data (2014) 
Whereas child benefits mainly serve to aid in the costs of raising a child, other non-contributory rights-based benefits mainly aim to guarantee a minimal living standard to the poorest in society as benefit schemes built around vertical redistribution, with (sometimes very strict) means-tests to identify the poorest families. In figure 3 we show the targeting indicators of all non-discretionary non-contributory benefits combined (housing allowance, social assistance, child support and inwork benefits, according to the OECD classification). The results indeed show that targeting is more outspoken for the total of non-contributory benefits than it is for child benefits alone. The US is an exception since the targeting design of the child benefit is based on TANF. Including food stamps and the earned income tax credit results in a somewhat less targeted design. Nonetheless, the US is one of the countries that most decisively intends to target families with low incomes. Another exception is Romania where including in-work benefits, social assistance and housing allowances leads to a nearly universal targeting score. This is due to the structure of the OECD Benefits and Wages output data, where it is assumed that it is the same family that earns these different percentages of the gross average wage, and hence makes the transition from social assistance to employment. Whereas this assumption in general is not too relevant, in Romania, it causes eligibility to a specific activation measure, where former social assistance beneficiaries keep on receiving their former benefit as a back-to-work bonus. Hence, under this specific assumption, this model family will receive social assistance for the full income distribution. In Greece and Italy, the targeting design indicator is exactly the same for child benefits as for all benefits together, as no other legally guaranteed non-contributory benefits existed in 2013, at least not for the model family included in our exercise. 
Figure 3. Targeting design indicator for legally guaranteed benefits, couple with 2 children, $0-220 \%$ of gross average wage

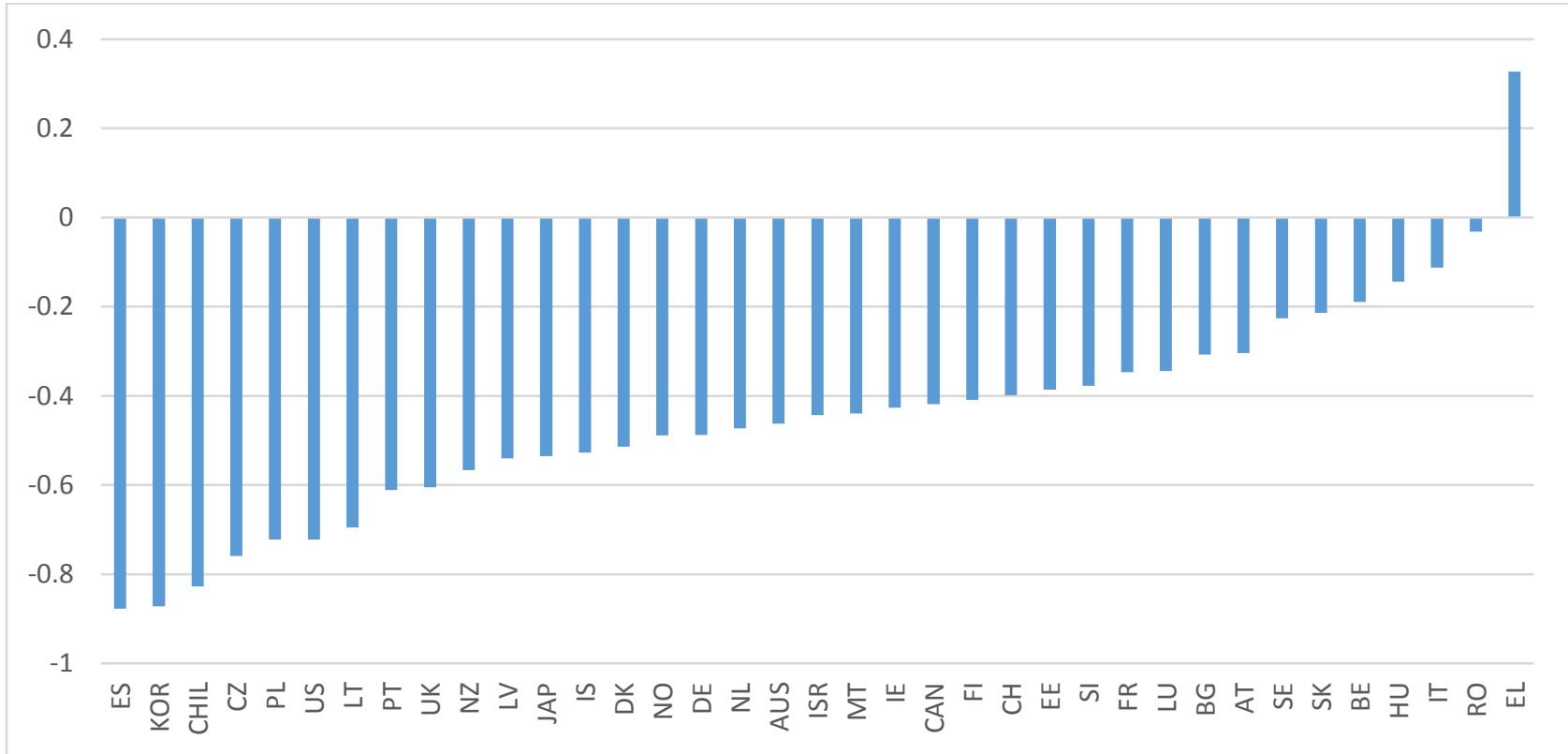

Note: Exact targeting indicator values are reported in Table A2 in the appendix.

Source: OECD Benefits and Wages (2014), own calculations.

Finally, a number of countries stand out because of their relatively limited targeting, even though the inclusion of social assistance, in-work benefits and housing allowances leads to a more targeted benefit design than child benefits do. In Slovakia, Sweden, Hungary and Belgium, the institutional targeting design indicator takes values between -0.23 and -0.14 . This is because of a relatively generous child benefit as compared to the value of the means-tested benefits (or a particularly ungenerous means-tested benefit as compared to the value of the universal benefits).

\subsection{Application 2: A crisis effect on targeting design?}

Tracking trends in targeting design allows to assess whether the crisis led to a substantial restructuring of the welfare state. Some authors have indeed argued that crises may represent windows of opportunity for policy makers to change or redirect path-dependent social policies (see Starke et al. 2013).

In the wake of the crisis, many international organizations, such as the IMF, called for more meanstested social programs as they favored an efficient use of limited public funds (see e.g. International Monetary Fund 2012). Also the European Commission called for more benefits targeted towards 
those households that would be more likely to spend the additional income (European Commission 2008). Several authors have since assessed which policy measures were taken in response to the crisis, generally focusing on a specific policy field. For instance, Marchal, Marx and Van Mechelen (2014, 2016) showed increased support to minimum income beneficiaries in the immediate aftermath of the onset of the financial crisis, that was however swiftly cut back as the crisis progressed. In line with Shahidi (2015) and Armingeon (2012), they found that substantial cutbacks were more likely in countries where the crisis was more severe. Also in the fields of labour market reforms, Clasen et al. (2012) found such a two-staged response pattern. This research mainly focused on specific benefit amounts, rules and conditions. Other authors adopted a more holistic approach, focusing on country case studies, finding a similar pattern of expansion followed by retrenchment (Starke et al. 2013; Farnsworth and Irving 2011; Dukelow 2012). An assessment of changes to the overall targeting design of benefits and benefit combinations over a broader income distribution would however provide a clearer indicator of intrusive changes to the overall organization of benefit schemes. In short, does the observed tinkering in the margin at different points in the distribution lead to a substantially different targeting design?

Cross-nationally and cross-temporally comparing targeting design across nations will show us whether the reported (relatively limited) changes in specific benefits made welfare states overall more targeted. In this section, we use the proposed targeting design measure to assess whether the organization of different assistance based benefits in combination has substantially been altered in the wake of the crisis. We look at the period 2001-2013 in order to identify whether changes were atypical. Figure 4 shows trends in the concentration coefficient of child benefits (as classified in the OECD model) for a one-earner couple with two children (aged 6 and 10), over an income range going from 0 to $220 \%$ of gross average wage gross income, whereas Figure 5 looks at all assistancebased benefits in combination. For the ease of presentation, we split countries in the commonly used Esping-Andersen grouping, although it should be kept in mind that this grouping is less suitable for assistance-based benefits ${ }^{7}$.

The main observation from figures 4 and 5 is that there is no common trend towards more or less targeting, nor over the entire period, nor when focusing on the years after the Great Recession. In contrast, there are large differences between countries.

\footnotetext{
7 The Eastern European countries are additionally split in two groups, to improve readability.
} 
Specifically for the targeting design of child benefits (Figure 4), targeting design generally did not change immediately after the crisis. It did become slightly less targeted in Germany, France, and, later on, in the US, but the scale of these changes was very limited and was moreover quickly reversed in the former country. Child benefits became more targeted in the UK, Portugal, and Lithuania. In all cases these were austerity measures, generally taken already a few years after the onset of the crisis. Child benefits did become somewhat more targeted in the Netherlands in 2008. Also in the Czech Republic, child benefits became (far) more targeted in 2008. Since the data refer to the situation in July 2008 (i.e. before the full onset of the crisis in most countries), it is rather unlikely that these changes in targeting design were actually crisis-driven. In the other countries, post-crisis changes seem to be in line with trends in earlier years. In Ireland, Belgium, Austria and the Scandinavian countries, targeting design remained universal over the entire period. All in all, substantial crisis-driven changes to targeting design are limited to a few countries where austerity measures made child benefits more targeted. 
Figure 4. Concentration coefficient of child benefit for a couple with 2 children, income range $0-220 \%$ AW, 2001-2015
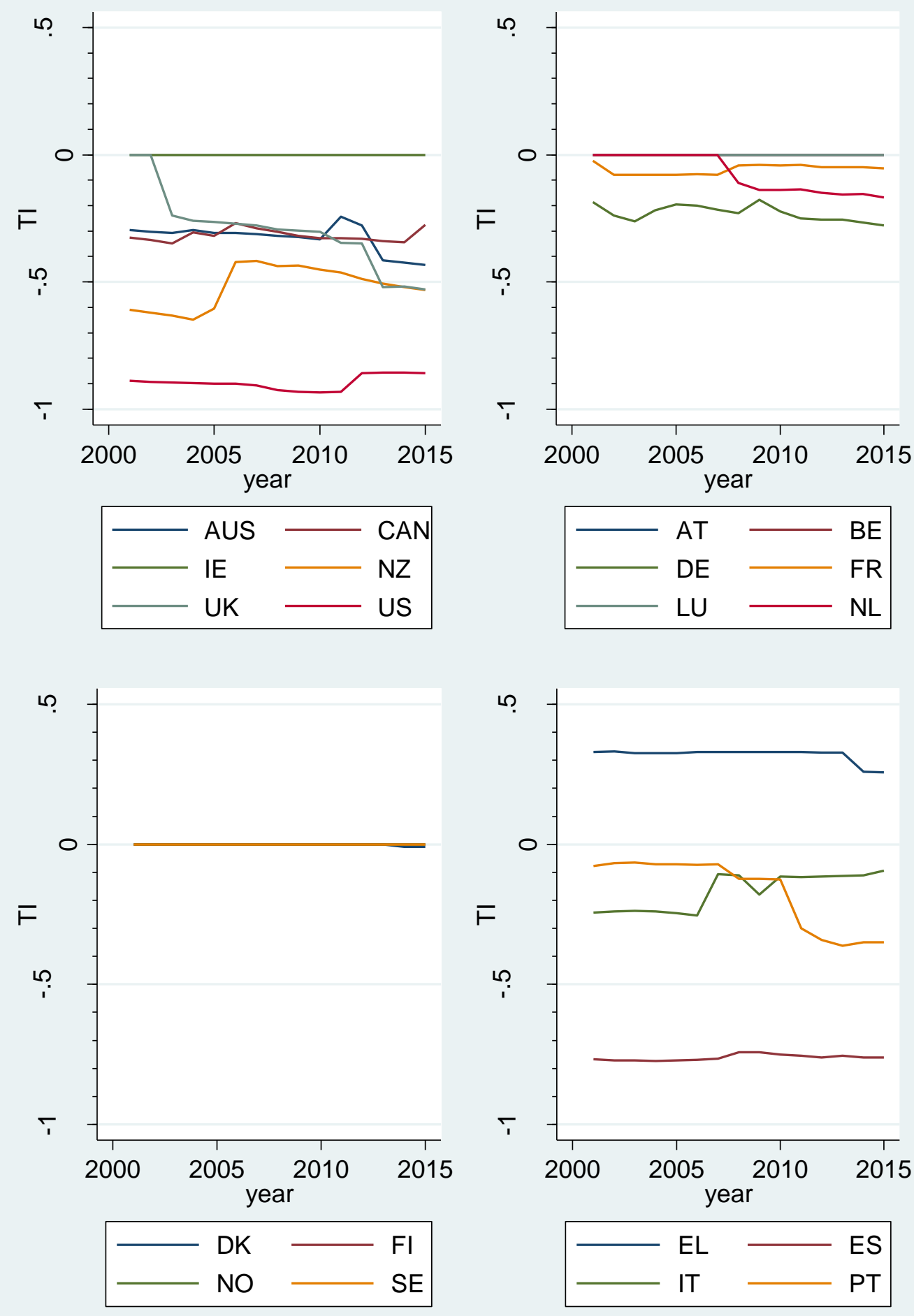
Figure 4. Concentration coefficient of child benefit for a couple with 2 children, income range $0-220 \%$ AW, 2001-2013 - ctd
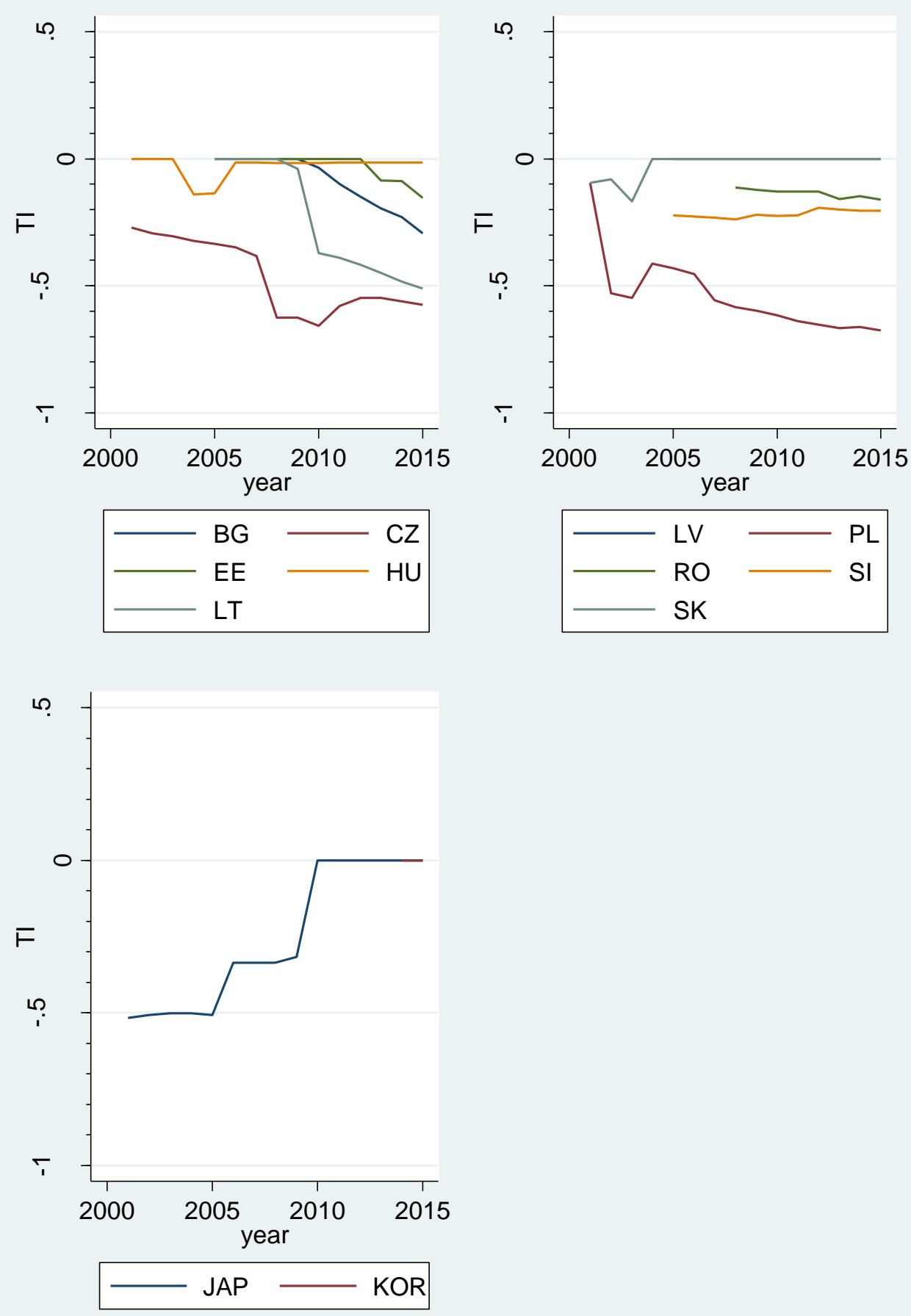

Note: no child benefits for the couple with 2 children model family in Korea.

Source: OECD Benefits and Wages (2014), own calculations 


\begin{abstract}
Also when taking account of the wider array of assistance benefits, including those specifically focused on in the calls from international organizations at the onset of the crisis, we find that crisis measures impacted on targeting design only in some cases. The clearest example is the expansion of the food stamp scheme in the US, which in the first crisis years became temporarily accessible to higher income households. Whereas this was clearly a substantial departure from traditionally strongly targeted support, it was only a temporary expansion. A similar (but more limited) temporary expansion appears to have occurred in Germany. In France, a shift towards more targeted benefits was permanent, but not a reaction to the crisis. Elsewhere, changes in the post crisis years were far more limited, or were in line with pre-crisis trends.
\end{abstract}


Figure 5. Concentration coefficient of assistance benefits for a couple with 2 children, income range $0-220$ $\%$ AW, 2001-2013
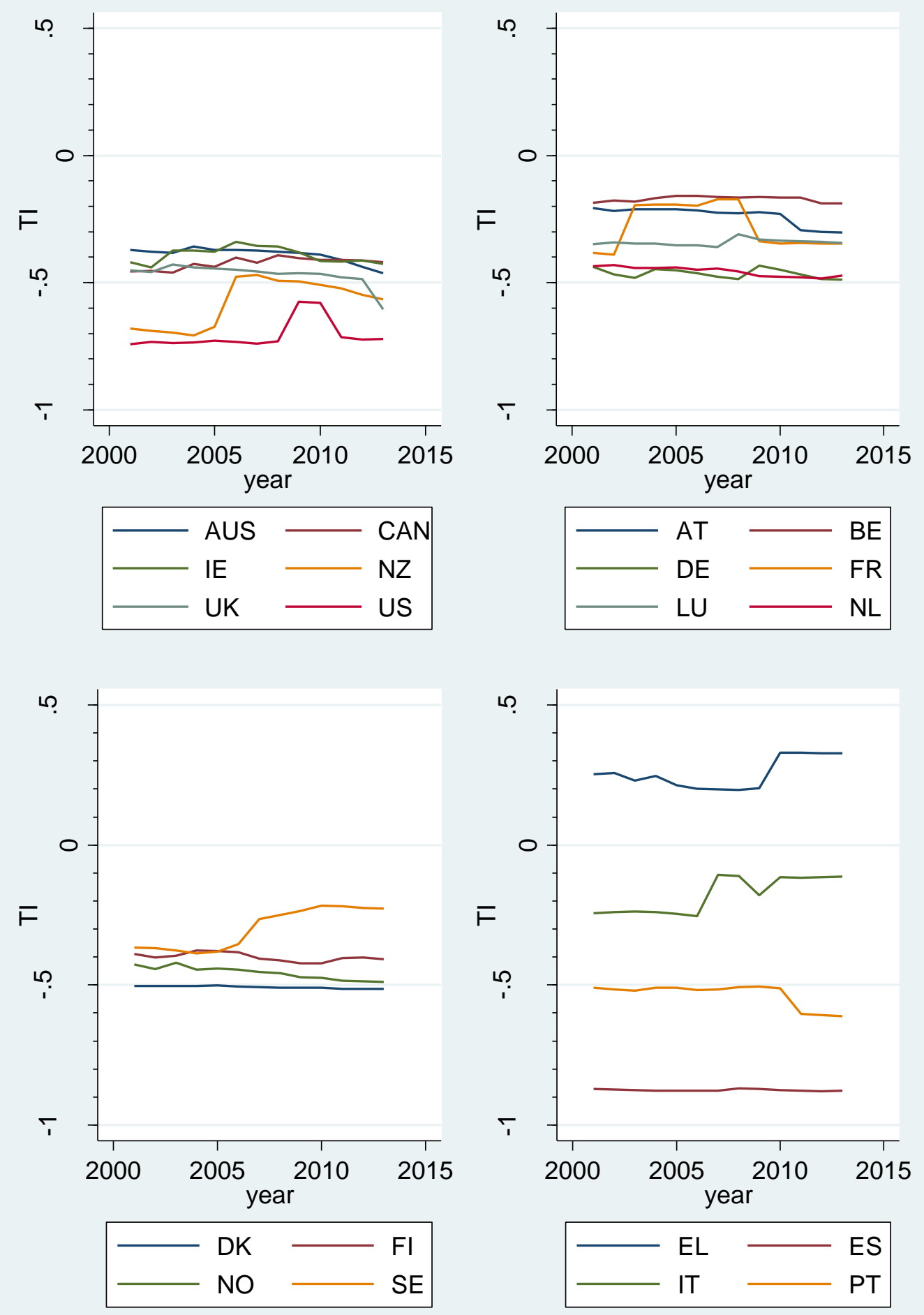
Figure 5. Concentration coefficient of assistance benefits for a couple with 2 children, income range 0 - 220 $\%$ AW, 2001-2013 - ctd
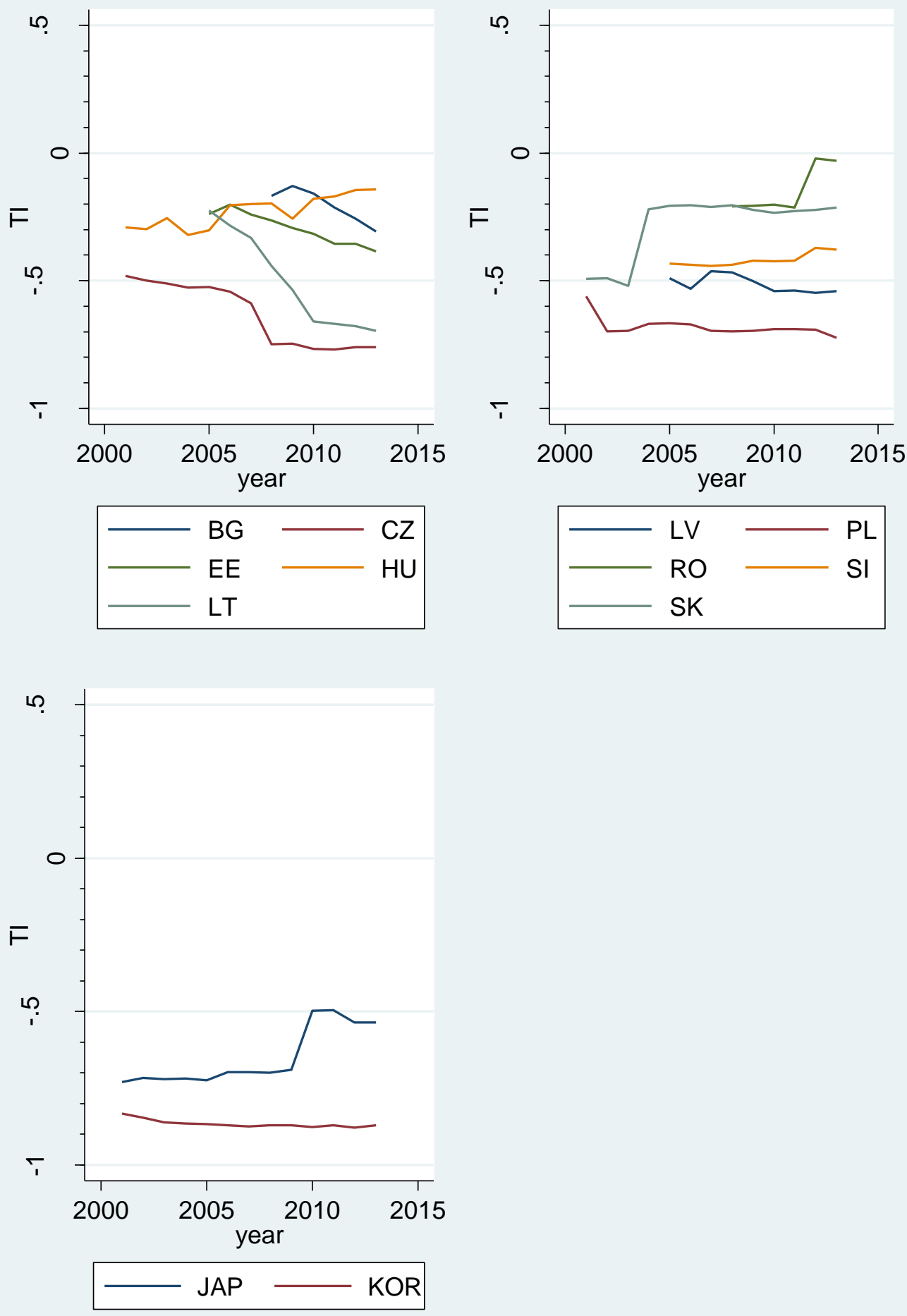

Source: OECD Benefits and Wages (2014), own calculations 
In sum, whereas targeting design did change due to crisis measures in a limited number of countries, generally the measures identified in the literature had no substantial impact on overall design. Moreover, bar some temporary measures, changes in targeting design only occurred after a few years in the crisis, as part of efforts to cut spending.

\subsection{Application 3: A short note on contributory benefits}

Measuring targeting intentions of non-contributory benefits is straightforward, and the concentration coefficient performs well in gauging the targeting design of these benefits. However, in many countries the bulk of the benefits are contributory ones. This poses additional challenges to uncover targeting intentions. In table 3, we calculate the concentration coefficient on the replacement rates for unemployment benefits, and on the actual unemployment benefit amounts. Here, too, we focus on a couple with 2 children, yet this time with previous earnings ranging from $0-200 \%$ of the average wage. Since the couple is unemployed, current earnings are zero and the benefit amounts usually depend on previous earnings.

Table 3 clearly illustrates the different logic of income replacement schemes. Based on the replacement rates (the unemployment benefit as a percentage of previous earnings), the concentration coefficient is negative in all countries, indicating that previous low earner families enjoy higher replacement rates. The closer to zero, the more the unemployment benefit system resembles a purely proportional system, with equal replacement rates regardless of previous earnings. In most countries however, measures such as benefit ceilings or minimal wage levels for entitlement distort such a purely proportional picture, and many countries ensure a relatively targeted system in terms of replacement rates.

Yet when focusing on benefit amounts, as we did in this paper, we come to an entirely different conclusion. Indeed, it follows from the logic of a contributory income replacement rates that families with previously high earnings will receive more in absolute terms in the event of job loss, compared with families with previously low earnings. Merely focusing on benefit amounts relative to previous earnings therefore shows a picture of targeting intentions towards higher incomes in almost all of the countries. We see some exceptions in those countries where unemployment benefits are flat-rate, as is the case in Australia, New Zealand and the United Kingdom. 
Table 3. Concentration coefficient of unemployment benefits relative to previous earnings (0-200\% average wage), couple with 2 children, 2013

\begin{tabular}{|c|c|c|}
\hline country & UB replacement rates & UB amounts \\
\hline AT & -0.152 & 0.195 \\
\hline AUS & -0.665 & 0.000 \\
\hline $\mathrm{BE}$ & -0.600 & 0.063 \\
\hline CAN & -0.117 & 0.221 \\
\hline $\mathrm{CZ}$ & -0.286 & 0.175 \\
\hline $\mathrm{DE}$ & -0.496 & 0.204 \\
\hline DK & -0.629 & 0.039 \\
\hline EL & -0.665 & 0.000 \\
\hline ES & -0.517 & 0.140 \\
\hline FI & -0.457 & 0.191 \\
\hline FR & -0.051 & 0.318 \\
\hline HU & -0.287 & 0.131 \\
\hline IE & -0.567 & 0.066 \\
\hline IS & -0.196 & 0.164 \\
\hline IT & -0.221 & 0.156 \\
\hline JAP & -0.388 & 0.190 \\
\hline KOR & -0.553 & 0.098 \\
\hline LU & -0.068 & 0.264 \\
\hline NL & -0.531 & 0.152 \\
\hline NO & -0.000 & 0.237 \\
\hline $\mathrm{NZ}$ & -0.665 & 0.000 \\
\hline PL & -0.216 & 0.104 \\
\hline PT & -0.165 & 0.223 \\
\hline SE & -0.512 & 0.096 \\
\hline UK & -0.665 & 0.000 \\
\hline US & -0.194 & 0.157 \\
\hline
\end{tabular}

Source: OECD Benefits and Wages (2014), own calculations

How one should assess targeting intentions in insurance-based benefits systems ultimately depends on the research question. Still, also for contributory benefits the concentration coefficient applied on institutional data yields intuitive results that are a reflection of policy design. 


\section{Limitations of the indicator}

The targeting design measure explored in this paper has both advantages and limitations. It does succeed in capturing intended targeting for a very specifically determined model family, and in distinguishing between more and less targeted benefits. Yet, as indicated by the comparison of the German and Portuguese child benefit design, background knowledge of the schemes remains necessary. Targeting design can be varied and in some countries has an outspokenly jagged outline. Summarizing such a distribution in one measure leaves important nuances untold. The quality of the institutional data is equally important. Seemingly small assumptions can have a large impact. How to treat back to work bonuses or refunded tax credits are only a few examples. For reasons of consistency, in this paper we follow the classification of the OECD although it is clear that an in-depth assessment (and perhaps even reclassification) of certain income components might be necessary for some countries.

In figure A1 in the appendix we contemplate how to assess (refunded) tax credits, who are akin to benefits in their social purposes. We checked the impact of an alternative classification, where the refunded part of income taxes was included as a benefit. This alternative classification did not substantially impact on the targeting design measures, as the benefit units entitled to assistance benefits generally overlaps with the benefit units who have negative tax liabilities after taking account of tax credits. Self-evidently, tax credits also aid households who only see their tax liabilities decreased. Here the different logics of targeting of benefit amounts and the progressivity of tax rates meet. Nor our, nor the tax progressivity measures succeed in combining both logics in one single measure. In our view, for those households who remain with positive tax liabilities, it would be most elegant to include the impact of tax credits in a progressivity measure of taxes, based on positive tax liabilities, and use this as a context variable to frame the targeting design of benefits.

We also compared the proposed targeting indicator to two other indicators proposed in the literature (the measures proposed by Jacques and Noël, and Van Lancker and Van Mechelen discussed above, see tables A3 and A4 in the appendix). Also, we assess the sensitivity of the indicator to changes to the underlying distribution (Table A5). Overall, correlations with the other two known targeting intentions indicators run in the expected direction, although they are weak. Some countries are assessed substantially different by the different indicators. 
It is important to note that the concentration coefficient needs to be calculated on exactly the same underlying income distribution to be comparable across countries and over time. If the underlying distribution of incomes differs across countries, e.g. in case institutional data stems from different sources, the concentration coefficient needs to be assessed in combination with the Gini index of that underlying distribution in order to make meaningful comparisons (see Marx et al. 2016). Finally, there are limits to the versatility of the concentration coefficient as an indicator of targeting intentions. It is not designed to cope with a limited number of observations and it cannot cope with negative amounts. This limits the form the underlying data can take, and limits the applicability of the concentration coefficient to assess the impact of net tax liabilities.

\section{Conclusion}

In this paper we propose, test and discuss an indicator to chart and compare targeting intentions across benefit schemes and countries, and over time. We propose to calculate the concentration coefficient of benefit amounts over a hypothetical income distribution for a specific model family, reflecting the rules and legislations of benefit systems across OECD countries. This approach builds on the use of model family simulations as indicators for the generosity of benefit schemes (e.g. Gough et al. 1996) and as indicators for the progressivity of tax systems (OECD 2015; Paturot et al. 2013) or benefit schemes (Nelson et al. 2016). We explore the usefulness of this approach in measure targeting intentions.

Overall, the proposed indicator performs well in reflecting targeting design. It is able to identify the degree of targeting built into benefit schemes. It can cope with non-linear targeting and complex set-ups of targeting design. The indicator reliably reflects policy changes, and can be interpreted intuitively. Finally, it isolates the issue of targeting from generosity or benefit levels. As such, the indicator enables to measure targeting intentions in complex welfare states.

Some issues remain however. The usefulness of the indicator depends heavily on the underlying (fictional) income distribution. For interpreting the results, background knowledge of the systems remains necessary. Also, in order to fully capture targeting design of the entire welfare state, including tax design and social insurance-based benefits, it is important to make a distinction between non-contributory and contributory benefit schemes. 
We presented a number of possible applications in this paper. In a next step, these applications could be further developed. More importantly, however, since the indicator summarizes policy design in one parameter, it can be applied in multivariate models. As such it becomes possible to empirically assess what design is needed to ensure efficient targeting, and to scrutinize political economy arguments regarding cross-class coalitions and redistribution. Whether targeting intentions instead of targeting outcomes are related to better or poorer redistributive outcomes has the potential to move forward the long-standing debate on the 'paradox of redistribution' in the years to come.

\section{References}

Akerlof, G. A. (1978). The Economics of "Tagging" as Applied to the Optimal Income Tax, Welfare Programs, and Manpower Planning. The American Economic Review, 68(1), 8-19. Armingeon (2012). The politics of austerity: what political parties can do and what markets want. Paper presented at the 2012 meeting of the American political science association, New Orleans, 30.08.2012-02.09.2012

Atkinson, A. B., Cantillon, B., Marlier, E., \& Nolan, B. (2002). Social Indicators: the EU and Social Inclusion. Oxford: Oxford University Press.

Barr, N. (2001). The welfare state as piggy bank: information, risk, uncertainty, and the role of the state. Oxford: Oxford University Press.

Bonoli, G. (2007). Time matters postindustrialization, new social risks, and welfare state adaptation in advanced industrial democracies. Comparative political studies, 40(5), 495-520, doi: $10.1177 / 0010414005285755$.

Bradshaw, J., \& Finch, N. (2002). A comparison of child benefit packages in 22 countries. Research Report (pp. 248). Norwich: UK Department for work and pensions.

Cantillon, B., \& Van Mechelen, N. (2014). Cracks in a policy paradigm - poverty reduction and social security: the case of Belgium. International Review of Sociology, 24(2), 270-290, doi:10.1080/03906701.2014.933026.

Clasen, J., Clegg, D., \& Kvist, J. (2012). European labour market policies in (the) crisis. ETUI Working Papers (pp. 30). Brussels: ETUI.

Dukelow, F. (2012). Financial crisis and reform in the Irish welfare state. Paper presented at the ESPAnet Annual conference, Edinburgh, 6-8 September 2012

European Commission (2008). Communication from the commission to the European council - A European Economic Recovery Plan. Brussels: European Commission.

Farnsworth, K., \& Irving, Z. (Eds.). (2011). Social policy in challenging times. Economic crisis and welfare systems. Bristol: The Policy Press.

Gough, I., Bradshaw, J., Ditch, J., Eardley, T., \& Whiteford, P. (1996). Social assistance in Oecd countries. Journal of European Social Policy, 7(1), 17-43.

Immervoll, H. (2012). Minimum-Income Benefits in OECD Countries. In D. Besharov, \& K. Couch (Eds.), Counting the Poor: New Thinking About European Poverty Measures and Lessons for the United States. Oxford: Oxford University Press. 
International Monetary Fund (2012). Greece: Request for extended arrangement under the extended fund facility - staff report. IMF Country Report. Washington: International Monetary Fund.

Jacques, O., \& Noël, A. (2015). Intentions and outcomes: the lasting relevance of the paradox of redistribution. Paper presented at the European consortium for political research general conference, Montréal, August 29, 2015

Joumard, I., Pisu, M., \& Bloch, D. (2012). Less income inequality and more growth - are they compatible? Part 3. Income redistribution via taxes and transfers across OECD countries. Economics Department Working Paper.

Land, K. C. (1983). Indicator Systems for Political, Economic, and Social Analysis. American Journal of Sociology, 88(5), 1078-1080, doi:10.1086/227793.

Marchal, S., Marx, I., \& Van Mechelen, N. (2014). The Great Wake-Up Call? Social citizenship and minimum income provisions in Europe in times of crisis. Journal of Social Policy, 43(2), 247-267, doi:10.1017/S0047279413000950.

Marchal, S., Marx, I., \& Van Mechelen, N. (2016). Minimum income schemes in the austerity tide. IZA Journal of European labor studies, 5(4), 1-20, doi:10.1186/s40174-016-0052-7.

Mitchell, D., Harding, A., \& Gruen, F. (1994). Targeting welfare. The Economic Record, 70(210), 315-340, doi:10.1111/j.1475-4932.1994.tb01850.x.

Moene, K. O., \& Wallerstein, M. (2001). Inequality, social insurance, and redistribution. American Political Science Review, 95(4), 485-516.

Musgrave, R. A., \& Thin, T. (1948). Income tax progression, 1929-48. Journal of Political Economy, 56(6), 498-514.

Nelson, K. (2007). Introducing SaMip: The social assistance and minimum income protection interim dataset. $S$-WpPEc: Swedish institute for social research.

Nelson, K. (2013). Social Assistance and EU Poverty Thresholds 1990-2008. Are European Welfare Systems Providing Just and Fair Protection Against Low Income? European Sociological Review, 29(2), 386-401, doi:10.1093/esr/jcr080.

Nelson, K., Bäckman, O., Doctrinal, L., \& Sirén, S. (2016). Understanding the paradox: why effective poverty alleviation still requires a secured middle class. Paper presented at the 23rd International Conference of Europeanists. Resilient Europe? , Philadelphia, April 1416,2016

Benefits and Wages: country specific files (2014). http://www.oecd.org/els/soc/benefitsandwagescountryspecificinformation.htm. Accessed 20.11.2014.

OECD (2015). Taxing wages 2015. Paris: OECD.

Paturot, D., Mellbye, K., \& Brys, B. (2013). Average personal income tax rate and tax wedge progression in OECD countries. OECD Taxation Working Papers: OECD Publishing.

Shahidi, F. V. (2015). Welfare capitalism in Crisis: A qualitative comparative analysis of labour market policy responses to the Great Recession. Journal of Social Policy, 44(4), 659-686.

Skocpol, T. (1991). Targeting within universalism: Politically viable policies to combat poverty in the United States. In C. Jencks, \& P. E. Peterson (Eds.), The urban underclass (pp. 411436). Washington, DC: The Brookings Institution.

Starke, P., Kaasch, A., \& Van Hooren, F. (2013). The Welfare State as Crisis Manager. Responses to Major Economic Crisis in Small Open Economies. Basingstokes: Palgrave MacMillan.

Van Kerm, P. (2009). Sgini. Generalized Gini and Concentration coefficients (with factor decomposition) in Stata. 
Van Lancker, W., \& Van Mechelen, N. (2015). Universalism under siege? Exploring the association between targeting, child benefits and child poverty across 26 countries. Social Science Research, 50, 60-75, doi:http://dx.doi.org/10.1016/j.ssresearch.2014.11.012.

Van Mechelen, N., Marchal, S., Goedemé, T., Marx, I., \& Cantillon, B. (2011). The CSB-Minimum Income Protection Indicators dataset (CSB-MIPI). CSB Working Paper Series (pp. 104). Antwerp: Herman Deleeck Centre for Social Policy, University of Antwerp.

Van Oorschot, W. J. H., \& Roosma, F. (2017). The social legitimacy of targeted welfare and welfare deservingness. In W. J. H. Van Oorschot, F. Roosma, B. Meuleman, \& T. Reeskens (Eds.), The social legitimacy of targeted welfare: attitudes to welfare deservingness (pp. 336). Cheltenham: Edward Elgar Publishing.

Whiteford, P., Mendelson, M., \& Millar, J. (2003). Timing it right? Tax credits and responding to income changes. Discussion paper. York: Joseph Rowntree Foundation. 


\section{Appendix}

Table A1. Representativity of the OECD model family simulation data: share of persons with a wage < $220 \%$ of average wage

\begin{tabular}{|c|c|c|}
\hline country & $\begin{array}{l}\text { active age }(16-64) \\
\text { persons }\end{array}$ & $\begin{array}{l}\text { active age persons living in couple families with two } \\
\text { children }\end{array}$ \\
\hline AT & $79 \%$ & $77 \%$ \\
\hline $\mathrm{BE}$ & $77 \%$ & $69 \%$ \\
\hline $\mathrm{BG}$ & $81 \%$ & $76 \%$ \\
\hline CY & $81 \%$ & $70 \%$ \\
\hline $\mathrm{CZ}$ & $78 \%$ & $73 \%$ \\
\hline DE & $76 \%$ & $73 \%$ \\
\hline DK & $83 \%$ & $74 \%$ \\
\hline $\mathrm{EE}$ & $81 \%$ & $73 \%$ \\
\hline ES & $77 \%$ & $72 \%$ \\
\hline FI & $79 \%$ & $71 \%$ \\
\hline FR & $81 \%$ & $73 \%$ \\
\hline GR & $74 \%$ & $65 \%$ \\
\hline HR & $76 \%$ & $68 \%$ \\
\hline HU & $80 \%$ & $74 \%$ \\
\hline IE & $79 \%$ & $72 \%$ \\
\hline IS & $88 \%$ & $84 \%$ \\
\hline IT & $72 \%$ & $69 \%$ \\
\hline LT & $80 \%$ & $75 \%$ \\
\hline LU & $79 \%$ & $77 \%$ \\
\hline $\mathrm{LV}$ & $82 \%$ & $78 \%$ \\
\hline MT & $78 \%$ & $75 \%$ \\
\hline NL & $79 \%$ & $73 \%$ \\
\hline NO & $86 \%$ & $81 \%$ \\
\hline PL & $80 \%$ & $69 \%$ \\
\hline $\mathrm{PT}$ & $80 \%$ & $73 \%$ \\
\hline RO & $75 \%$ & $71 \%$ \\
\hline SE & $85 \%$ & $79 \%$ \\
\hline SI & $79 \%$ & $70 \%$ \\
\hline SK & $81 \%$ & $76 \%$ \\
\hline UK & $80 \%$ & $72 \%$ \\
\hline US & $76 \%$ & $64 \%$ \\
\hline $\mathrm{CA}$ & $75 \%$ & $63 \%$ \\
\hline JP & $42 \%$ & $70 \%$ \\
\hline $\mathrm{AU}$ & $74 \%$ & $66 \%$ \\
\hline IL & $74 \%$ & $59 \%$ \\
\hline
\end{tabular}

Sources: EU countries: EU-SILC 2015 (incomes 2014), non EU-countries: Luxemburg Income Study (LIS) database (waves ranging from 2008-2014) 
Table A2. Targeting design of child benefits and all non-contributory rights-based benefits for a couple with 2 children, over income range $0-220 \%$ of gross average wage, 2013, OECD countries

\begin{tabular}{|c|c|c|}
\hline country & Child benefits (figure 1) & $\begin{array}{c}\text { Non-contributory rights-based } \\
\text { benefits (figure 2) }\end{array}$ \\
\hline AUS & -0.41 & -0.46 \\
\hline AT & 0.00 & -0.30 \\
\hline $\mathrm{BE}$ & 0.00 & -0.19 \\
\hline BG & -0.19 & -0.31 \\
\hline CAN & -0.34 & -0.42 \\
\hline CHIL & -0.71 & -0.83 \\
\hline $\mathrm{CH}$ & 0.11 & -0.40 \\
\hline $\mathrm{CZ}$ & -0.55 & -0.76 \\
\hline $\mathrm{DE}$ & -0.26 & -0.49 \\
\hline DK & 0.00 & -0.51 \\
\hline $\mathrm{EE}$ & -0.08 & -0.39 \\
\hline EL & 0.33 & 0.33 \\
\hline ES & -0.76 & -0.88 \\
\hline FI & 0.00 & -0.41 \\
\hline FR & -0.05 & -0.35 \\
\hline HU & -0.01 & -0.14 \\
\hline IE & 0.00 & -0.43 \\
\hline IS & -0.23 & -0.53 \\
\hline ISR & 0.00 & -0.44 \\
\hline IT & -0.11 & -0.11 \\
\hline JAP & 0.00 & -0.53 \\
\hline KOR & & -0.87 \\
\hline LT & -0.45 & -0.69 \\
\hline LU & 0.00 & -0.34 \\
\hline LV & 0.00 & -0.54 \\
\hline MT & -0.19 & -0.44 \\
\hline NL & -0.16 & -0.47 \\
\hline $\mathrm{NO}$ & 0.00 & -0.49 \\
\hline $\mathrm{NZ}$ & -0.51 & -0.57 \\
\hline PL & -0.67 & -0.72 \\
\hline PT & -0.36 & -0.61 \\
\hline RO & -0.16 & -0.03 \\
\hline SE & 0.00 & -0.23 \\
\hline SI & -0.20 & -0.38 \\
\hline SK & 0.00 & -0.21 \\
\hline TUR & n.a. & n.a. \\
\hline UK & -0.52 & -0.60 \\
\hline US & -0.86 & -0.72 \\
\hline
\end{tabular}

Source: OECD Benefits and Wages (2015), own calculations 
Figure A1. Comparison of targeting intentions measures with reclassified refundable tax credits

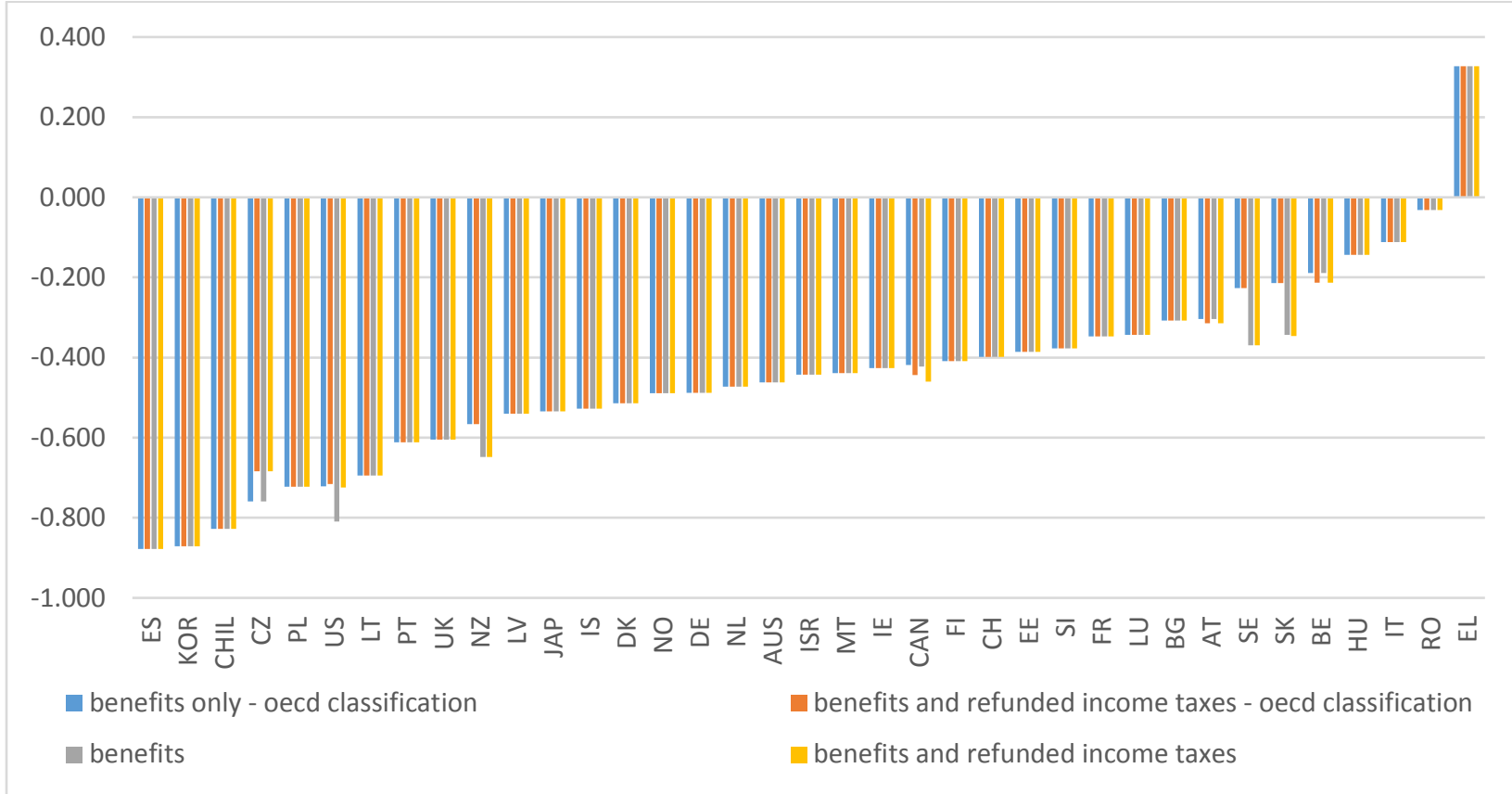

Note: benefits only: oecd classification: the oecd classification followed through this paper. Benefits and refunded income taxes: oecd classification: includes the impact of an alternative classification of tax credits, which includes the value of the actually refunded part of tax credits in the assessment of benefit targeting. Benefits: excludes tax credits assessed by the OECD as inwork benefits or child benefits. Benefits and refunded income taxes: includes the full amount of refunded income tax credits.

Source: OECD Benefits and Wages (2015), own calculations 
Table A3. Comparison to targeting indicator proposed by Van Lancker and Van Mechelen (2015), couple with 2 children in 2009

\begin{tabular}{lccc}
\hline & TIVLVM (2015) & TICC & TIVLMVM(OECD) \\
\hline AT & -0.0043 & -0.06 & -0.00151 \\
BE & -0.0649 & 0.03 & -0.00066 \\
BG & 0 & -0.07 & -0.00284 \\
CZ & -0.4759 & -0.17 & -0.02432 \\
DE & 0 & -0.15 & -0.00278 \\
EE & 0.1469 & -0.03 & -0.00214 \\
EL & 0.3756 & 0.18 & 0.000155 \\
ES & 0.1724 & 0.03 & -0.01368 \\
FI & 0 & -0.21 & -0.00409 \\
FR & 0.0885 & -0.16 & -0.00207 \\
HU & 0 & -0.10 & -0.00523 \\
IE & -0.0533 & -0.08 & -0.00143 \\
IT & -0.0561 & 0.00 & 0.005126 \\
LT & 0.1007 & -0.39 & -0.01791 \\
LU & -0.0257 & -0.09 & -0.00165 \\
LV & 0.2499 & -0.09 & -0.00238 \\
NL & -0.0299 & -0.19 & -0.00376 \\
NO & 0 & -0.27 & -0.00557 \\
PL & 0.1083 & -0.22 & -0.00845 \\
PT & -0.1379 & -0.29 & -0.00605 \\
RO & -0.1824 & -0.15 & -0.0042 \\
SE & 0 & -0.11 & -0.00243 \\
SI & -0.3865 & -0.14 & -0.00316 \\
SK & 0.1587 & -0.06 & -0.00103 \\
UK & -0.76 & -0.35 & -0.00709 \\
\hline correlation & 1 & 0.48 & 0.29 \\
\hline Note TIVIVM & \\
\hline
\end{tabular}

Note: TIVLVM (2015): TIVLVM for child support (the difference in net income for a family with and without children) as reported in Van Lancker and Van Mechelen (2015), based on 3-4 family types for 2009; TICC: the concentration coefficient indicator proposed in this paper, calculated on the 2009 OECD Benefits and Wages simulation data for child support as defined in Van Lancker and Van Mechelen; TIVLVM(OECD): TIVLVM calculated on the full income range in the OECD Benefits and Wages data for 2009. The relatively low correlation with the original TIVLVM gives reason to suspect the importance of including a relatively broad income range for the family type under consideration.

Source: Van Lancker and Van Mechelen (2015); OECD Benefits and Wages (2014), own calculations 
Table A4. Comparison to targeting indicator proposed by Noël \& Jacques

\begin{tabular}{lccc}
\hline & $\begin{array}{c}\text { Means-tested working } \\
\text { age spending as \% of } \\
\text { social spending (2011) }\end{array}$ & $\begin{array}{c}\text { TI, all non- } \\
\text { contributory benefits, } \\
\text { for couples with two } \\
\text { children, 2011 }\end{array}$ & $\begin{array}{c}\text { TI, all non- } \\
\text { contributory benefits, } \\
\text { for lone parents with } \\
\text { two children, 2011 }\end{array}$ \\
\hline AT & 3.61 & -0.29 & -0.23 \\
BE & 5.34 & -0.17 & -0.14 \\
CZ & 1.81 & -0.77 & -0.80 \\
DE & 6.74 & -0.47 & -0.46 \\
EL & 2.68 & 0.33 & 0.32 \\
ES & 9.01 & -0.88 & -0.88 \\
FI & 5.01 & -0.40 & -0.15 \\
FR & 6.65 & -0.34 & -0.26 \\
HU & 2.88 & -0.17 & -0.12 \\
IE & 31.92 & -0.42 & -0.37 \\
IT & 3.91 & -0.12 & -0.12 \\
LU & 3.11 & -0.34 & -0.24 \\
NL & 11.68 & -0.48 & -0.30 \\
NO & 3.49 & -0.48 & -0.33 \\
PL & 3.66 & -0.69 & -0.70 \\
PT & 5.6 & -0.60 & -0.56 \\
SE & 2.73 & -0.22 & -0.08 \\
SI & 7.85 & -0.42 & -0.45 \\
SK & 5.65 & -0.23 & -0.28 \\
UK & 20.55 & -0.48 & -0.47 \\
US & 17.12 & -0.71 & -0.74 \\
\hline correlation & 1 & -0.25 & -0.26 \\
\hline SOurce: & 1 & -0.25 & . \\
\hline
\end{tabular}

Source: OECD SOCX, as described in Jacques and Noël (2015); OECD Benefits and Wages (2014), own calculations 
Table A5. Targeting indicator for all assistance based benefits awarded to a couple with 2 children, over different income ranges (defined as \% of gross average wage), 2013

\begin{tabular}{|c|c|c|c|c|c|}
\hline country & $0-220$ & $0-200$ & $50-220$ & $30-220$ & $80-180$ \\
\hline AUS & -0.46 & -0.41 & -0.42 & -0.43 & -0.27 \\
\hline AT & -0.30 & -0.31 & -0.03 & -0.13 & 0.00 \\
\hline $\mathrm{BE}$ & -0.19 & -0.20 & 0.00 & 0.00 & 0.00 \\
\hline BG & -0.31 & -0.24 & -0.25 & -0.26 & -0.02 \\
\hline CAN & -0.42 & -0.40 & -0.28 & -0.33 & -0.12 \\
\hline CHIL & -0.83 & -0.81 & -0.82 & -0.79 & -0.89 \\
\hline $\mathrm{CH}$ & -0.40 & -0.41 & 0.00 & -0.12 & 0.00 \\
\hline $\mathrm{CZ}$ & -0.76 & -0.74 & -0.72 & -0.80 & -0.81 \\
\hline $\mathrm{DE}$ & -0.49 & -0.44 & -0.37 & -0.42 & -0.10 \\
\hline DK & -0.51 & -0.50 & -0.41 & -0.48 & -0.23 \\
\hline EE & -0.39 & -0.40 & -0.02 & -0.07 & 0.00 \\
\hline EL & 0.33 & 0.33 & 0.21 & 0.25 & 0.13 \\
\hline ES & -0.88 & -0.87 & -0.98 & -0.87 & \\
\hline FI & -0.41 & -0.41 & -0.18 & -0.29 & -0.04 \\
\hline FR & -0.35 & -0.35 & -0.17 & -0.26 & -0.07 \\
\hline HU & -0.14 & -0.15 & -0.04 & -0.06 & -0.02 \\
\hline IE & -0.43 & -0.42 & -0.26 & -0.33 & -0.13 \\
\hline IS & -0.53 & -0.50 & -0.35 & -0.40 & -0.20 \\
\hline ISR & -0.44 & -0.45 & -0.18 & -0.32 & 0.00 \\
\hline IT & -0.11 & -0.07 & -0.26 & -0.21 & -0.18 \\
\hline JAP & -0.53 & -0.53 & -0.38 & -0.47 & -0.10 \\
\hline KOR & -0.87 & -0.86 & & -0.96 & \\
\hline LT & -0.69 & -0.66 & -0.71 & -0.71 & -0.59 \\
\hline LU & -0.34 & -0.35 & -0.09 & -0.21 & 0.00 \\
\hline LV & -0.54 & -0.55 & 0.00 & -0.24 & 0.00 \\
\hline MT & -0.44 & -0.44 & -0.20 & -0.26 & -0.06 \\
\hline NL & -0.47 & -0.47 & -0.26 & -0.32 & -0.03 \\
\hline NO & -0.49 & -0.50 & -0.07 & -0.27 & 0.00 \\
\hline NZ & -0.57 & -0.52 & -0.54 & -0.56 & -0.41 \\
\hline PL & -0.72 & -0.69 & -0.77 & -0.74 & -0.78 \\
\hline PT & -0.61 & -0.57 & -0.45 & -0.53 & -0.32 \\
\hline RO & -0.03 & -0.03 & -0.03 & -0.04 & -0.02 \\
\hline SE & -0.23 & -0.24 & -0.01 & -0.07 & 0.00 \\
\hline SI & -0.38 & -0.35 & -0.30 & -0.33 & -0.26 \\
\hline SK & -0.21 & -0.21 & -0.13 & -0.15 & -0.13 \\
\hline UK & -0.60 & -0.57 & -0.60 & -0.61 & -0.32 \\
\hline US & -0.72 & -0.69 & -0.83 & -0.79 & -0.87 \\
\hline correlation & 1 & 0.996231 & 0.835593 & 0.927508 & 0.72224 \\
\hline
\end{tabular}

Source: OECD Benefits and Wages (2014), own calculations 